\title{
Analysis of efficiency of drilling equipment use in mining operations
}

\author{
Yuriy Masaev ${ }^{1}$, Vladislav Masaev ${ }^{1}$, and Yuriy Drozdenko ${ }^{1,2^{*}}$ \\ ${ }^{1}$ T.F. Gorbachev Kuzbass State Technical University, 28 Vesennyaya str., Russia \\ ${ }^{2}$ Branch of T.F. Gorbachev Kuzbass State Technical University in Prokopievsk, 19a Nogradskaya str., \\ Russia
}

\begin{abstract}
When developing coal and ore deposits by underground method, it is necessary to carry out a large volume of preparatory mine workings using drilling and blasting operations. Minerals are found in rocks under various conditions and their physical and mechanical properties change in a wide range. Under such conditions, it is necessary to use drilling machines this different to the principle of action and structural features. The article considers geometric parameters of roc cutters, peculiarities of drilling modes, affecting energy intensity and drilling productivity in rocks with different strength coefficient.
\end{abstract}

\section{Introduction}

When developing mineral deposits by underground method, it is necessary to build a large complex of preparatory mine workings. An important task is the selection and application of effective means of drilling mechanization, the development of schemes and parameters of drilling and drilling operations and methods of explosion energy control, which make it possible to increase the overall efficiency of the drilling and blasting complex, reduce labor intensity, and increase the rate of drilling and blasting workings.

Efficiency of preparation of mine workings is inextricably connected with productivity of used drilling machines, which provide required rate of carrying out of mine workings, and this depends on physical and mechanical properties of rocks, modes and methods of drilling, quality of drilling tool, depth and number of blast hole, number of simultaneously working drilling machines. The main task is to establish the relationship between drilling efficiency and the rate of mining operations based on the planned volumes of mining operations.

Main factors affecting drilling performance:

- physical and mechanical properties of rocks;

- drilling mode;

- cutting tool configuration;

- volume of drilling works in the cycle;

- operational reliability of drilling machines;

- depth of continuous drilling;

- number of drilling machines simultaneously participating in the work;

${ }^{*}$ Corresponding author: duv.gmik@,kuzstu.ru 
- method of drilling fines removal.

Depending on conditions of mine workings and properties of rocks, machines of rotary, rotative-percussive and percussive drill can carry out drilling of holes. In strong rocks, only rotative-percussive and percussive drilling can be used.

As is known, the main indicator of the evaluation of the rotative-percussive drilling mode is the relationship of the specific feed of the tool with the axial force, rotation speed and geometric parameters of the rock cutter. As is known, the main indicator of the evaluation of the rotative-percussive drilling mode is the relationship of the specific feed of the tool with the axial force, rotation speed and geometric parameters of the rock cutter. The dependence of the drilling speed on the axial force can be expressed by the equation:

$$
V_{\delta}=k\left(P_{n}-P_{0}\right)
$$

where $\mathrm{k}$ - efficiency factor of rotative-percussive drilling,; $\mathrm{Pn}$ - min rig pulldown, P0 - acting rig pulldown.

The graphical dependence of the drilling speed on the rotational speed of the drill bit under various rig pulldown conditions is shown in Fig. 1.

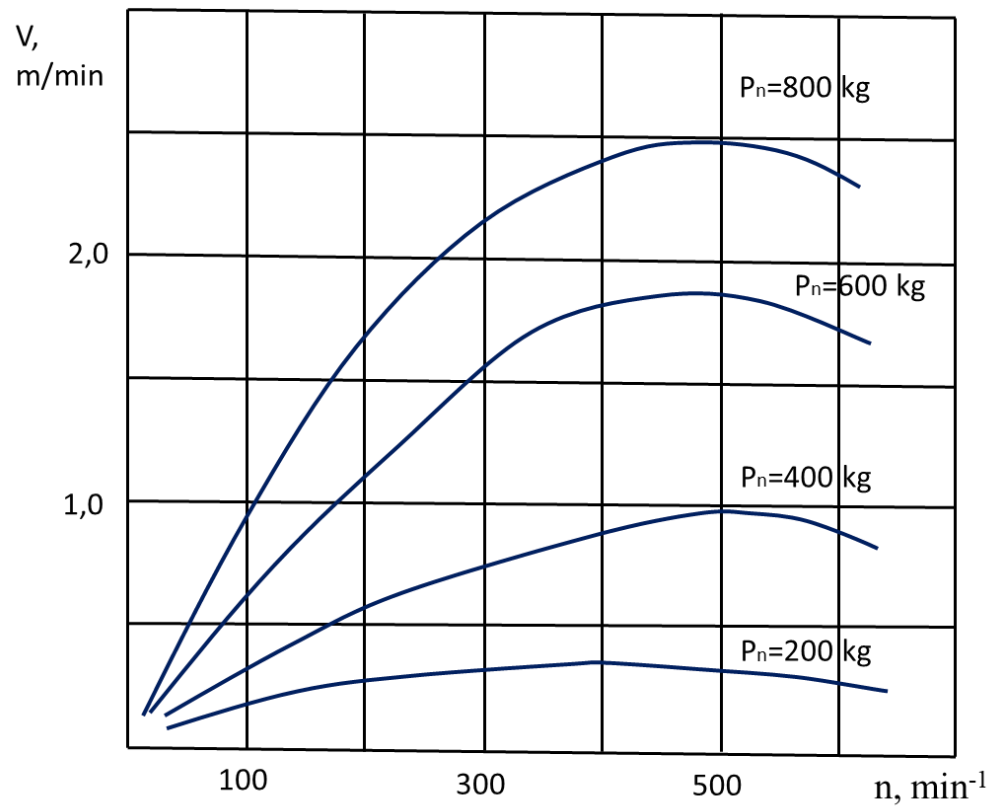

Fig. 1. Dependence of the drilling speed on the rotational speed of the drill bit under various rig pulldown conditions

The dependence of the productivity of drilling holes on the depth of bite at different numbers of revolutions of the drill bit is shown in Fig. 2. 


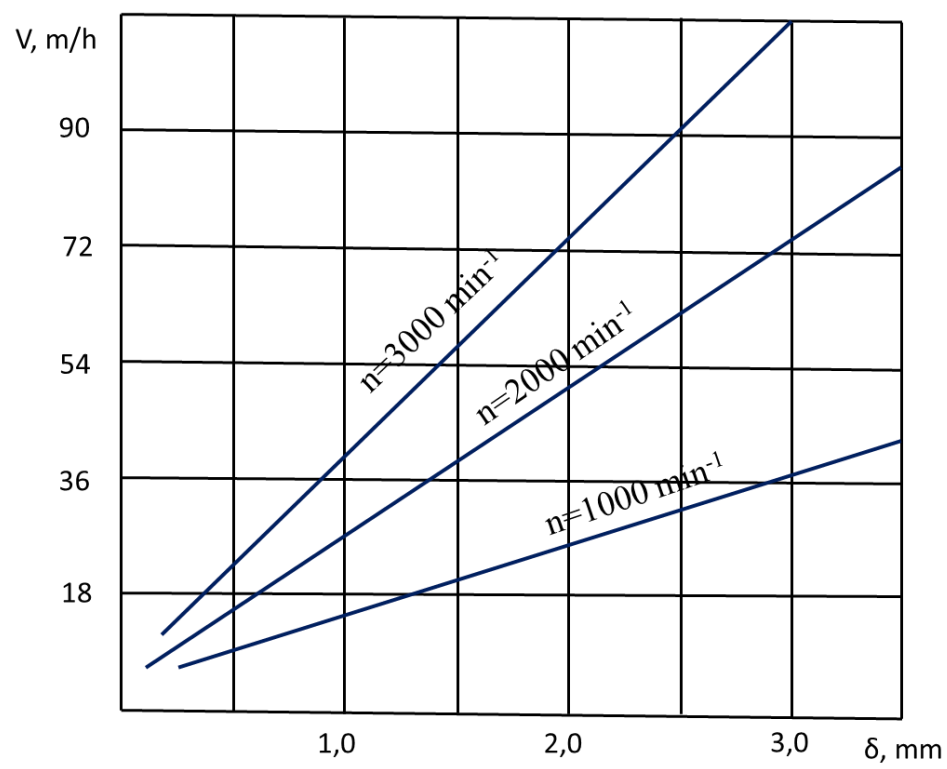

Fig. 2. Dependence of the productivity of drilling holes on the depth of bite $(\delta)$ at different numbers of revolutions of the drill bit

With the same rig pulldown, the drilling speed depends on the rotational speed of the drill rod with the cutter. It was found that the drilling speed at a constant rig pulldown increases in proportion to the rotation speed only up to a certain limit, then this proportionality is violated.

Research shows that the increase in specific feed depending on the axial force is not the same in rocks of different hardness. With an increase in the hardness of rocks, the degree of influence of the axial force on the specific feed has almost no effect, but the wear of the tool blades increases, and therefore it is inappropriate to increase it. With an increase in the rotational speed of the tool, its specific feed decreases. This leads to the fact that up to a certain value of the rotational speed of the tool, the drilling speed will increase, and then may decrease.

The rational limit of the rotational speed of the drilling tool when drilling rocks with a strength factor $\mathrm{f}=6-10$ is $400-1500 \mathrm{~min} 1$. In rotary percussion drilling, in contrast to rotary drilling, with an increase in the feed force to $1200-1500 \mathrm{~kg}$, the drilling speed in mediumhard rocks increases by 4.5-5.0 times, and in strong rocks by 2.2-3,5 times.

For medium-hard rocks, drilling machines are effective with an increase in feed of 800-1200 $\mathrm{kg}$ with a drill rotation speed of 200-500 min 1, a frequency of 3000-4000 impacts per minute with an impact energy of 3-5 kgm. When drilling hard rocks ( $\mathrm{f} \geq 14)$, the rotational speed of the drill should be reduced to 100-300 $\mathrm{min}^{1}$.

Recommended modes for rotary and rotary percussion drilling are shown in Table 1.

Table 1. Recommended modes for rotary and rotary percussion drilling

\begin{tabular}{|l|c|c|c|c|c|c|}
\hline & \multirow{2}{*}{ Unit of } & \multicolumn{2}{|c|}{ rotary drilling } & \multicolumn{3}{c|}{ rotary percussion drilling } \\
\cline { 3 - 7 } & measur & $f=6-8$ & $f=8-12$ & $f=6-8$ & $f=8-12$ & $f \geq 12-14$ \\
& $\mathbf{e}$ & & & & & 1200 \\
\hline Rig pulldown & $\mathrm{kg}$ & 1000 & 1200 & 1000 & 1200 \\
\hline Rotation speed & $\mathrm{min}^{-1}$ & $400-500$ & $200-400$ & $400-500$ & $200-400$ & $100-200$ \\
\hline
\end{tabular}




\begin{tabular}{|l|c|c|c|c|c|c|}
\hline $\begin{array}{l}\text { Rotational } \\
\text { torque }\end{array}$ & $\mathrm{kgm}$ & $8-12$ & $10-12$ & $10-15$ & $15-20$ & $12-20$ \\
\hline $\begin{array}{l}\text { Impact } \\
\text { frequency }\end{array}$ & $\mathrm{min}^{-1}$ & - & - & $\begin{array}{c}3000- \\
3500\end{array}$ & $300-400$ & $3500-6000$ \\
\hline Impact energy & $\mathrm{kgm}$ & - & - & 3,0 & $3-5$ & $4-5$ \\
\hline
\end{tabular}

Analysis of the data of various researchers [1-4] proves that the rational rotational speed is in the range of 100-300 rpm. There is an inverse relationship between the frequency of a rotation and the strength of rocks.

The drilling speed is greatly influenced by the number of blows applied to the tool per revolution. Increasing or underestimating the number of impacts can result in increased energy consumption, decreased drilling speed, or hardening and tool breakage. For the range of rocks with $\mathrm{f}=4-20$, the rational number of strokes is $10-50$ beats/rev. Fewer blows correspond to rocks with a lower strength coefficient. If increase the energy of a single blow, then the number of blows can be reduced.

Drilling performance is highly dependent on the geometry of the drilling tool. In fig. 3 shows the influence of the angle of sharpening of the drill bit on the productivity of drilling holes. It can be seen from the figure that with a decrease in the sharpening angle from $70^{\circ}$ to $50^{\circ}$, the drilling productivity increases 2 times for any rock strength. However, the permissible limit for reducing the angle of sharpening of the drilling cutter is determined by its strength.

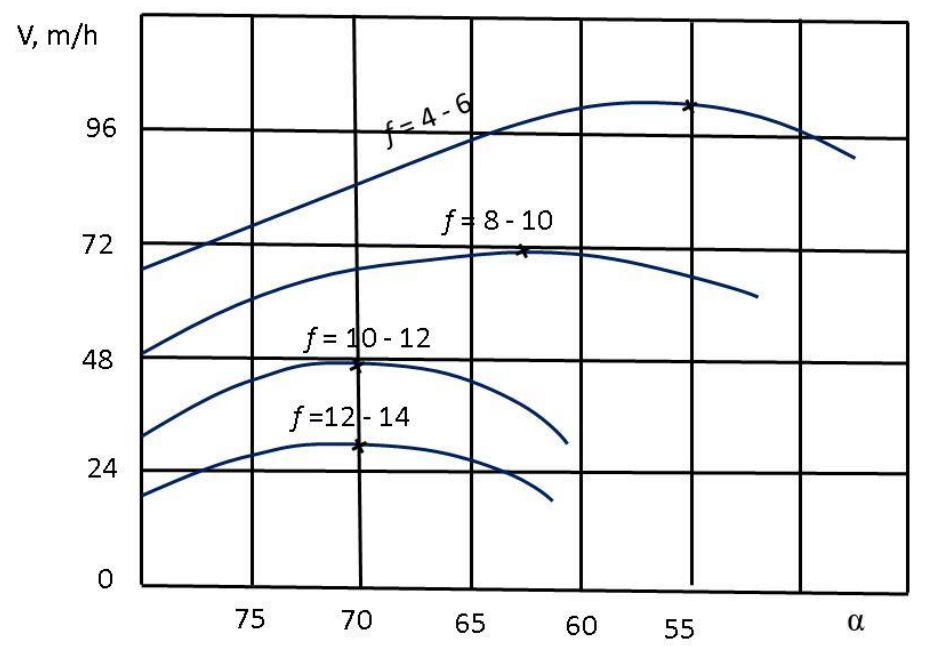

Fig. 3. Influence of the angle of sharpening of the drill bit on the productivity of drilling holes $(\mathrm{P}=1500 \mathrm{~kg}, \mathrm{n}=275 \mathrm{~min}-1$.)

Researchers [5] show that often the angle of sharpening of cutters does not correspond to the necessary conditions for effective burial of cutters upon impact and the mode of cutting the rock during rotation. When struck at the moment of rotation of such a rock cutter, the impact force is "washed out" at the bottom of the hole, and when rotating, the cutter leaves the hole without cutting off the chips, which significantly increases the energy consumption of drilling and reduces the speed of drilling the holes.

In rotary percussion drilling, it is necessary, due to the effective geometry of the cutter, to ensure a clear burial of the cutter into the rock during impact and cutting off the rock shavings without the cutter coming out of the burial. For this purpose, we have proposed a new modification of the drill bit, created based on the serially produced BU-43-25 bit [6]. 
The reason for this was the research carried out at the ore mines of JSC "EVRAZ ZSMK" in the Tashtagol city [7] during mining workings in hard rocks with $\mathrm{f}=8-18$.

For drilling boreholes, it is used both percussion drilling with perforators on pneumatic supports and perforators from drilling carriages, as well as rotary percussion drilling with SBU-2M rigs. But, as in the first and in the second cases, the KDP 40-25 chisel bit is used and in some cases BU-43-25.

Such bits do not provide high drilling performance, the resulting pattern of rock destruction does not correspond to the used drilling method. These crowns have a large negative rake angle $\left(-45^{\circ}\right.$ and $\left.-25^{\circ}\right)$ and do not have a cut in the central part, therefore, for their deepening and shearing of the layer, the rock requires an increased axial load. When using such crowns, very high wear of the cutting blades is observed.

The experimental bit was distinguished by the fact that it had a central cut with a width of 0.05-0.06 m, a double clearance angle, and the front-cutting edges had a concave surface with a radius of curvature of $20 * 10-3 \mathrm{~m} .5^{\circ}$ directly at the blade, and the second $25^{\circ}-$ at a feather height of $5 * 10-3 \mathrm{~m}$.

The use of the concave surface of the bit blade had the goal of increasing the depth of the bit and reducing the possibility of the bit coming out of the formed hole at the moment of impact and subsequent removal of the rock layer. The double clearance angle maintains the necessary strength of the bit blades. And in combination, this bit geometry allows you to achieve an increase in drilling productivity with lower rig pulldown.

The results of testing various types of drill bits when drilling holes are presented in Table 2 .

Table 2. Recommended modes for rotary and rotary percussion drilling

\begin{tabular}{|c|c|c|c|c|c|}
\hline $\begin{array}{c}\text { Drill bit } \\
\text { type }\end{array}$ & $\begin{array}{c}\text { Drilled } \\
\text { holes, pcs }\end{array}$ & $\begin{array}{c}\text { Depth of } \\
\text { holes, m }\end{array}$ & $\begin{array}{c}\text { Drilling } \\
\text { time, h }\end{array}$ & $\begin{array}{c}\text { Drilling } \\
\text { speed, m / } \\
\text { h. }\end{array}$ & $\begin{array}{c}\text { Used drill } \\
\text { bits per } \\
\text { cycle, pcs. }\end{array}$ \\
\hline KDP 40-25 & 11 & 2,0 & 1,72 & 12,8 & 3 \\
\hline BU-43-25 & 13 & 2,0 & 1,56 & 16,7 & 3 \\
\hline Experiment & 17 & 2,0 & 1,7 & 20 & 3 \\
\hline
\end{tabular}

The research results showed that the use of experimental bits gives an increase in the drilling speed in rocks with $\mathrm{f}=8-10$ by $46-50 \%$, in rocks with $\mathrm{f}=10-12$ by $60 \%$, and in rocks with $\mathrm{f}=12-14$ - up to $70-80 \%$. In all studies, except for the geometry of the drill bits, all other operating parameters were identical.

\section{Conclusion}

Thus, the following indicators have been established.

1. The experimental bit turned out to be the most effective when drilling rocks $f=8-14$.

2. With the use of an experimental bit, the drilling time of the hole was significantly reduced, and the productivity of the drill increased by an average of $32 \%$. The cost of drilling decreased by $33 \%$.

3. A decrease in the drilling speed occurs because due to the concave front face of the feathers of the experimental bit, the rake angle decreases and the penetration into the rock decreases. However, this allows you to maintain the required strength of the feathers and ensure high wear resistance of the bit. When regrinding, only the back plate is machined at a double angle, while the rake angle increases from $-10^{\circ}$ to $-30^{\circ}$. 


\section{References}

1. R. I. Sukhov, A. G. Polanskij, A. S. Regotunov, Gorny`j informaczionnoanaliticheskij byulleten', 8, 285 (2007)

2. A. Khoreshok, L. Kantovich, D. Kuziev, V. Kuznetsov, E. Preis, E3S Web Of Conferences, 03004 (2017)

3. R. R. Dautov, Gorny`j zhurnal, 8, 84 (2005)

4. A. M. Keropyan, D. A. Kuziev A. E. Krivenko, Springer Nature Switzerland AG 2020 Proceedings of the 5th International Conference on Industrial Engineering (2019)

5. M. V. Sekretov, Gorny`j informaczionno-analiticheskij byulleten`, 12, 211 (2014)

6. V. V. Timonin, V. N. Karpov, Fundamental`ny`e i prikladny`e voprosy`gorny`kh nauk, 3(2), 172 (2016)

7. M. V. Pavlenko, N. G. Barnov, D. A. Kuziev, K. N. Kenzhabaev, M. V. Monzoev, Ugol, (1), 36 (2020)

8. Yu. A. Masaev, V. Yu. Masaev, Innovaczii v tekhnologiyakh i obrazovanii, 155 (2018)

9. Pat. 156934 RF, MPK E21D 11/00 Yu. A. Masaev, V. A. Karasev, V. Yu. Masaev, I. K. Kostinecz, V. N. Khomchenko (2015)

10. A. I. Kopy`tov, Yu. A. Masaev, V. Yu. Masaev, I. K. Kostinecz, Vestnik KuzGTU, 2(108), 56 (2015)

11. S. V. Mazein, A. N. Pankratenko, A. G. Polyankin, E. A. Sharshova, Tunnels and Underground Cities: Engineering and Innovation meet Archaeology, Architecture and Art-Proceedings of the WTC 2019 ITA-AITES World Tunnel Congress, 45, 2663 (2019) 